\title{
Increased Risk Of Early-Onset Neonatal Sepsis After Laser Surgery For Twin-to-Twin Transfusion Syndrome
}

\author{
Liselotte E. M. van Kempen, ${ }^{1}$ Depeng Zhao, ${ }^{1}$ Sylke J. Steggerda, ${ }^{1}$ Vincent Bekker, ${ }^{2}$ \\ Johanna M. Middeldorp, ${ }^{3}$ Dick Oepkes, ${ }^{3}$ and Enrico Lopriore ${ }^{1}$ \\ ${ }^{1}$ Division of Neonatology, Department of Pediatrics, Leiden University Medical Center, Leiden, the Netherlands \\ ${ }^{2}$ Division of Pediatric Infectious Diseases, Department of Pediatrics, Leiden University Medical Center, Leiden, the \\ Netherlands \\ ${ }^{3}$ Division of Fetal Medicine, Department of Obstetrics, Leiden University Medical Center, Leiden, the Netherlands
}

\begin{abstract}
Objective: To investigate the occurrence of early-onset neonatal sepsis (EOS) in twin-twin transfusion syndrome (TTTS) managed with laser surgery.

Study design: We performed a prospective cohort study of all consecutive TTTS cases treated with laser surgery (TTTS group) delivered at the Leiden University Medical Center. We recorded the occurrence of EOS, defined as a positive blood culture $\leq 72$ hours postpartum (proven sepsis) or administration of a full course of antibiotics due to risk factors or signs of sepsis, in the absence of a positive blood culture (suspected sepsis). Perinatal variables in the TTTS group were compared with uncomplicated monochorionic twins (no-TTTS group). A multivariate model was generated, examining the association between EOS and gestational age at birth, interval between laser surgery and birth, anterior placenta, laser period (first study period: 2002-2008; second study period: 2009-2015), and preterm premature rupture of membranes (PPROM).

Results: The rates of combined suspected and proven EOS in the TTTS group and no-TTTS group were $16 \%(68 / 416)$ and $10 \%(55 / 542)$, respectively (relative ratio [RR] 1.74, 95\% confidence interval [CI] 1.19 2.55). Multivariate analysis showed that EOS in the TTTS group was independently associated with lower gestational age at birth (odds ratio [OR] $0.75,95 \% \mathrm{Cl} 0.63-0.88$ ), first study period (OR $2.25,95 \% \mathrm{Cl}$ 1.08-4.67) and PPROM (OR 2.47, 95\% Cl 1.28-4.75).

Conclusion: The rate of EOS in the TTTS group is low, but increased compared to the no-TTTS group. EOS in TTTS is independently associated with premature delivery, earlier laser period, and PPROM.
\end{abstract}

Keywords twin-twin transfusion syndrome, laser surgery, early-onset neonatal sepsis

TTTS is a severe condition complicating about $10 \%$ of monochorionic-diamniotic twin pregnancies (Lewi et al., 2008). Laser surgery is the optimal treatment for severe TTTS. Although the neonatal outcome has significantly improved after introduction of laser surgery, several complications are reported, such as PPROM, clinical, or histologic chorioamnionitis, recurrent or reversed TTTS, and postlaser twin anemia-polycythemia sequence (TAPS). PPROM is partly due to the specific nature of the fetoscopic intervention itself, in which a fetoscope is introduced into the amniotic cavity causing iatrogenic PPROM (Chalouhi et al., 2011; Roberts et al., 2014; Salomon et al., 2010; Senat et al., 2004; Yamamoto et al., 2005). Previous studies also demonstrated that the risk of chorioamnionitis and EOS is increased after invasive intrauterine procedures, such as amniocentesis or fetal blood sampling, in both singletons and twins (André et al., 2000; Brambati et al., 1990; d'Ercole et al., 2003; Hamoda \& Chamberlain, 2002; Kim et al., 2015; Soman et al., 1985; Workman \& Philpott-Howard, 1997). EOS is usually caused by bacterial pathogens, most commonly group B streptococcus or Escherichia coli, transmitted vertically from mother to infant before or during

RECEIVED 5 February 2016; ACCEPTED 5 March 2016. First published online 3 May 2016.

ADDRESS FOR CORRESPONDENCE: Enrico Lopriore MD PhD, Division of Neonatology, Department of Pediatrics, Leiden University Medical Center, Leiden, the Netherlands. E-mail: e.lopriore@lumc.nl 
delivery, and is one of the leading causes of neonatal mortality and morbidity (Naeye et al., 1971; Stoll et al., 2011; Weston et al., 2011). The risk of EOS following laser surgery for TTTS has, however, not yet been studied. The purpose of this study was to investigate the occurrence and risk factors of EOS after laser surgery for the treatment of TTTS.

\section{Materials and Methods \\ Design and Study Population}

All consecutive monochorionic twins delivered at the Leiden University Medical Center between March 2002 and April 2015 were eligible for this study. We included all monochorionic twins with TTTS treated with laser surgery (TTTS group) and compared them with a control group of uncomplicated monochorionic twins (no-TTTS group). Monochorionic twins with TTTS not managed with laser surgery and TAPS cases were excluded. We also excluded monochorionic twins with single or double fetal demise. These twins had to be excluded since sepsis workup was not performed, preventing the diagnosis of EOS. TTTS was diagnosed according to the Eurofetus criteria, defined as a maximal vertical pocket (MVP) of $<2 \mathrm{~cm}$ in the donor combined with a MVP of $>8 \mathrm{~cm}$ in the recipient before 20 weeks' gestation and $>10 \mathrm{~cm}$ thereafter (Senat et al., 2004). Staging of TTTS was defined according to Quintero's system (Quintero et al., 1999). The procedure of laser surgery for TTTS was published previously (Slaghekke, Lewi et al., 2014). Since 2008, the Solomon laser technique was introduced to reduce the risk of residual anastomoses and associated post-operation complications (Slaghekke, Lopriore et al., 2014). We thus divided the study period into two groups, that is, the first group from 2002 to 2008 (first study period) and the second group from 2009 to 2015 (second study period). Diagnosis of TAPS was based on previously published international criteria (Slaghekke et al., 2010).

\section{Outcome Variables}

The following perinatal variables were recorded, including gestational age at laser surgery, study period (first study period: 2002-2008; second study period: 2009-2015), placental localization, gestational age at birth, birth weight and birth weight discordance, mode of delivery, maternal fever $\left(\geq 38{ }^{\circ} \mathrm{C}\right)$, use of epidural anesthetics during labor, and PPROM ( $<37$ weeks gestational age for $>24$ hours). Data from maternal vaginal or urinary cultures were mostly not available and therefore not recorded. After birth, routine blood tests were performed in all preterm neonates that were born before the gestational age of 37 weeks. C-reactive protein (CRP) levels and immature/total neutrophil ratios (I/T ratio) were documented within the first 72 hours after birth. Elevated CRP was defined as a level $>20 \mathrm{mg} / \mathrm{L}$. An I/T ratio $>0.22$ was suggestive of infection (Polin, 2012). Blood cultures were performed within 72 hours after birth in all children with suspected perinatal infection. Diagnosis of
EOS was based on a positive blood culture within the first 72 hours postpartum (proven EOS) or the necessity for administration of a full course (5-7 days) of antibiotics due to perinatal risk factors and/or clinical signs of neonatal infection, though without a positive blood culture (suspected EOS). Blood cultures were evaluated for the chance of contamination. When a coagulase negative staphylococcus was found, these were only considered proven EOS if there were clinical and/or laboratory signs (CRP $>20 \mathrm{mg} / \mathrm{L}$ or I/T ratio $>0.22$ ) of infection. Risk factors for perinatal infection included one or more of the following items: maternal group B streptococcal colonization, maternal bacteriuria or infection, preterm birth (gestational age $<37$ weeks) following spontaneous labor, ruptured membranes $>24$ hours in preterm birth, maternal fever $\left(\geq 38{ }^{\circ} \mathrm{C}\right)$ or parenteral antibiotics given to the mother for (suspected) invasive bacterial infection (Dutch Society of Obstetrics and Gynaecology, 2012). The primary outcome was the occurrence of proven and/or suspected EOS. Secondary outcomes were CRP and I/T ratio in the first 72 hours after birth. Potential risk factors for EOS that were studied included gestational age at laser surgery, gestational age at birth, interval between laser surgery and birth, anterior placenta, study period (first study period: 2002-2008; second study period: 2009-2015), and PPROM.

\section{Statistical Analysis}

The Kolmogorov-Smirnov test was used to assess the normality of continuous variables. Student's $t$-test or the Mann-Whitney test were applied to analyze continuous variables, where appropriate. A chi-square test or Fisher exact test was used to compare dichotomous data. Paired variables were compared using the McNemar or Wilcoxon signed rank test, if applicable. The results were displayed as median and interquartile range (IQR), mean and range or number and percentage, where appropriate. The potential risk factors for EOS were analyzed in a univariable regression model (generalized estimating equation). The factors significantly associated with EOS in the univariate analysis were further used to build a multivariable regression model (generalized estimating equation) to assess their independence in relation to EOS, because pair-wised comparison in twins is possible in this binominal model. The results of correlation and risk factor analysis were displayed as OR and 95\% CI. Statistical significance was assumed if $p<.05$ in all analyses, besides the univariate analysis $(p<.10)$. Statistical analysis was performed using IBM SPSS Statistics 22.0 ${ }^{\circledR}$ (IBM Corporation, Armonk, New York, USA).

\section{Results}

During the study period, 479 eligible twin pairs with two live-born neonates were delivered at our hospital and included in the study, of which $208(43 \%)$ were in the TTTS group after laser surgery and 271 (57\%) in the noTTTS group. The baseline characteristics of the two study 
TABLE 1

Demographics and Baseline Characteristics

\begin{tabular}{|c|c|c|c|c|c|}
\hline & TTTS group $(n=208)$ & Missing & No-TTTS group $(n=271)$ & Missing & $p$ value \\
\hline Epidural during labor & $43(21 \%)$ & $43(21 \%)$ & $57(21 \%)$ & $72(27 \%)$ & .44 \\
\hline Maternal fever $\left(\geq 38^{\circ} \mathrm{C}\right)$ & $29(14 \%)$ & $30(14 \%)$ & $17(6 \%)$ & $25(9 \%)$ & $<.01$ \\
\hline Caesarian section & $83(40 \%)$ & $2(1 \%)$ & $116(43 \%)$ & $1(0.4 \%)$ & .41 \\
\hline Gestational age at birth - weeks $^{a}$ & $32.7(30.1-35.6)$ & & $34.9(31.7-36.3)$ & $1(0.4 \%)$ & $<.01$ \\
\hline Birth weight - grams ${ }^{b}$ & $1765(1271-2139)$ & & $2049(1520-2580)$ & & $<.01$ \\
\hline Birth weight discordance - \%b & $11.0(4.7-21.1)$ & & $11.3(5.5-24.0)$ & & .84 \\
\hline PPROM ( $>24$ hours) $)^{b, c}$ & $116(28 \%)$ & & $28(5 \%)$ & & $<.01$ \\
\hline Interval between PPROM and birth - hours ${ }^{b}$ & $1.7(0.0-54.4)$ & & $0.3(0.0-6.4)$ & & $<.01$ \\
\hline
\end{tabular}
variables the data were complete. ${ }^{c}$ Denotes the number of fetus instead of twin pairs.

TABLE 2

Primary and Secondary Outcomes in the TTTS Group and Control Group

\begin{tabular}{|c|c|c|c|c|c|c|c|}
\hline & & $\begin{array}{l}\text { TTTS group } \\
(n=416)^{a}\end{array}$ & Missing & $\begin{array}{l}\text { No-TTTS group } \\
(n=542)^{a}\end{array}$ & Missing & $p$ value & OR $[95 \% \mathrm{Cl}]^{\mathrm{b}}$ \\
\hline \multirow[t]{3}{*}{ Early-onset neonatal sepsis } & Overall & $68(16 \%)$ & $2(1 \%)$ & $55(10 \%)$ & $0(0 \%)$ & $<.01$ & $1.13[0.74-1.71]$ \\
\hline & Suspected & $58(14 \%)$ & - & $53(10 \%)$ & - & .04 & $0.95[0.62-1.46]$ \\
\hline & Proven & $10(2 \%)$ & - & $2(0.4 \%)$ & - & $<.01$ & $5.03[1.08-23.54]$ \\
\hline \multirow{3}{*}{\multicolumn{2}{|c|}{$\begin{array}{l}\text { C-reactive protein }-\mathrm{mg} / \mathrm{L} \\
\text { Elevated C-reactive protein }(>20 \mathrm{mg} / \mathrm{L}) \\
\text { Immature/total neutrophil ratio }\end{array}$}} & $7.0(1.0-104.0)$ & 95 (23\%) & $4.1(1.0-68.0)$ & 177 (33\%) & $<.01$ & - \\
\hline & & $28(7 \%)$ & 95 (23\%) & $21(4 \%)$ & 177 (33\%) & .13 & - \\
\hline & & $0.10(0.05-0.18)$ & $334(80 \%)$ & $0.06(0.05-0.09)$ & 450 (83\%) & $<.01$ & - \\
\hline
\end{tabular}

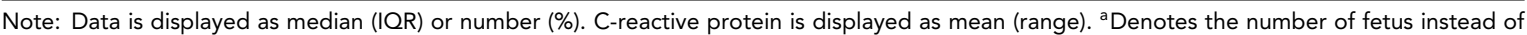
twin pairs. ${ }^{b}$ Corrected for gestational age at birth.

groups are summarized in Table 1. In the TTTS group, 14\% $(28 / 208)$ of the twin pairs were Quintero stage 1, 32\% $(67 / 208)$ stage 2, 51\% (105/208) stage 3, and 4\% (8/208) stage 4 . Median gestational age at laser surgery was 20 weeks (IQR 18-23 weeks). In the no-TTTS group, selective fetal growth restriction occurred in 65/271 (24\%) twin pairs, and $14 / 271$ (5\%) twin pairs were monoamniotic.

A comparison of primary and secondary outcomes between the TTTS group and no-TTTS group is shown in Table 2. The rate of proven EOS was 2\% (10/416) in the TTTS group and $0.4 \%(2 / 542)$ in the no-TTTS group (relative ratio [RR] $6.67,95 \%$ CI $1.45-30.59, p=.02)$. The rate of suspected EOS was $14 \%(58 / 416)$ in the TTTS group and $10 \%(53 / 542)$ in the no-TTTS group (RR 1.50, 95\% CI $1.01-2.24, p=.04$ ). The overall rate of EOS (proven or suspected) was significantly higher in the TTTS group compared to the no-TTTS group, $16 \%$ versus $10 \%$ respectively (RR 1.74, 95\% CI 1.19-2.55, $p<.01$ ). In the TTTS group after laser surgery, CRP and I/T ratio were also significantly increased compared to the no-TTTS group (both $p<.01$ ). After controlling for gestational age at birth, no difference in suspected EOS was detected in the TTTS group compared to the no-TTTS group (OR 0.95, 95\% CI 0.62-1.46, $p=.82$ ), but the OR of proven EOS was still increased (OR 5.03, 95\% CI 1.08-23.54, $p=.04$ ).

Analysis between ex-donors and ex-recipients in the TTTS group showed no difference in suspected or proven EOS (Table 3). However, the occurrence of PPROM was significantly higher in ex-recipients than in ex-donors, 69/206 (34\%) versus 46/206 (22\%) respectively (RR 1.75, 95\% CI $1.13-2.71 p=.01)$. Overall, EOS occurred in $62 \%(42 / 68)$ of cases in both neonates within the same twin pair and in only one neonate of the twin pair in the remaining $38 \%$ $(26 / 68)$ of EOS cases.

Univariate analysis of potential risk factors for the occurrence of EOS in TTTS managed with laser surgery showed that EOS was associated with lower gestational age at birth (OR 0.75, 95\% CI 0.67-0.83, $p<.01$ ), shorter interval between laser surgery and birth (OR 0.89, 95\% CI 0.84-0.95, $p<.01$ ), anterior placenta (OR 1.89, 95\% CI 0.99-3.63, $p=.06$ ), first study period (OR 2.32, 95\% CI 1.20-4.47, $p=.01$ ), and PPROM (OR 3.74, 95\% CI 2.06-6.81, $p<$ $.01)$. After multivariate analysis, only lower gestational age at birth (OR 0.75, 95\% CI 0.63-0.88, $p<.01$ ), first study period (OR 2.25, 95\% CI 1.08-4.67, $p=.03$ ) and PPROM (OR 2.47, 95\% CI 1.28-4.75, $p<.01$ ) were independently associated with the occurrence of EOS (Table 4).

In the group of neonates with proven EOS in the TTTS group, $60 \%(6 / 10)$ of infections was due to infection with gram positive bacteria (coagulase negative staphylococcus, $n=4$ with elevated CRP 13, 101, 68, $75 \mathrm{mg} / \mathrm{L}$, respectively; Staphylococcus aureus, $n=1$, Enterococcus faecalis, $n=$ 1) and $40 \%(4 / 10)$ of infections was due to gram negative bacteria (Escherichia coli, $n=2$, Klebsiella pneumoniae, $n=2$ ). In the two cases with proven EOS in the control group, infection was due in both cases to coagulase negative staphylococcus, with CRP 33 and $67 \mathrm{mg} / \mathrm{L}$, respectively.

\section{Discussion}

This is the first study to investigate the occurrence of EOS following laser surgery for the treatment of TTTS. Our 
TABLE 3

Comparison Between the Ex-Donor and the Ex-Recipient Twins in TTTS Managed with Laser Surgery

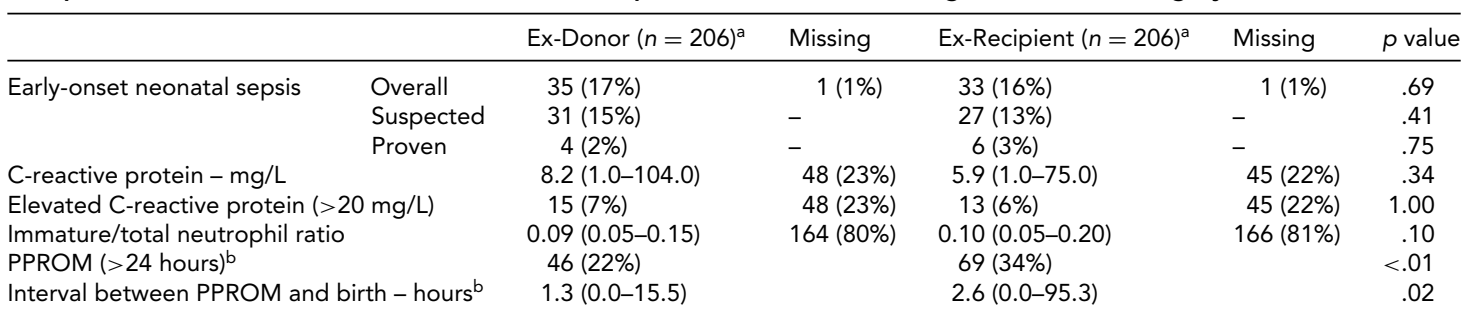

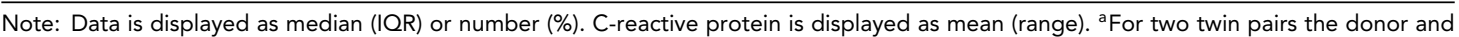
recipient were unknown. ${ }^{b}$ For these variables the data were complete.

TABLE 4

Analysis of Risk Factors for Early-Onset Neonatal Sepsis in TTTS Group Treated with Laser Surgery

\begin{tabular}{|c|c|c|c|c|c|c|}
\hline & $\begin{array}{l}\text { Neonates with } \\
\text { proven or } \\
\text { suspected EOS } \\
(n=68)\end{array}$ & $\begin{array}{l}\text { Neonates without } \\
\text { proven or } \\
\text { suspected EOS } \\
(n=346)\end{array}$ & $\begin{array}{l}\text { Univariate OR } \\
{[95 \% \mathrm{Cl}]}\end{array}$ & $p$ value & $\begin{array}{l}\text { Multivariate OR } \\
{[95 \% \mathrm{Cl}]}\end{array}$ & $p$ value \\
\hline $\begin{array}{l}\text { Gestational age at } \\
\text { laser - weeks }\end{array}$ & $20.0(16.3-23.0)$ & $20.0(18.0-23.0)$ & $0.97[0.87-1.08]$ & .58 & - & - \\
\hline $\begin{array}{l}\text { Gestational age at } \\
\text { birth - weeks }\end{array}$ & $30.1(28.0-31.9)$ & $33.4(30.4-35.7)$ & $0.75[0.67-0.83]$ & $<.01$ & $0.75[0.63-0.88]$ & $<.01$ \\
\hline $\begin{array}{l}\text { Time interval between } \\
\text { laser and birth - } \\
\text { weeks }\end{array}$ & $10.4(7.0-13.8)$ & $13.3(10.0-16.0)$ & $0.89[0.84-0.95]$ & $<.01$ & 1.04 [0.93-1.15] & .50 \\
\hline $\begin{array}{l}\text { Anterior placenta } \\
\text { localization, yes }\end{array}$ & $36(53 \%)$ & $129(37 \%)$ & 1.89 [0.99-3.63] & .06 & $1.54[0.75-3.14]$ & .24 \\
\hline $\begin{array}{l}\text { Anterior placenta } \\
\text { localization, no }\end{array}$ & 32 (47\%) & 217 (63\%) & & & & \\
\hline $\begin{array}{l}\text { First study period: } \\
\text { 2002-2008 }\end{array}$ & 39 (57\%) & 127 (37\%) & $2.32[1.20-4.47]$ & .01 & $2.25(1.08-4.67]$ & .03 \\
\hline $\begin{array}{l}\text { Second study period: } \\
2009-2015\end{array}$ & 29 (43\%) & 219 (63\%) & & & & \\
\hline $\begin{array}{l}\text { PPROM (>24 hours), } \\
\text { yes }\end{array}$ & $36(53 \%)$ & $80(23 \%)$ & $3.74[2.06-6.81]$ & $<.01$ & $2.47[1.28-4.75]$ & $<.01$ \\
\hline $\begin{array}{l}\text { PPROM (>24 hours), } \\
\text { no }\end{array}$ & 32 (47\%) & 266 (77\%) & & & & \\
\hline
\end{tabular}

findings show that the rate of EOS in TTTS treated with laser surgery is slightly increased compared to monochorionic twins without invasive fetoscopic intervention. Risk factor analysis shows that EOS after laser surgery for TTTS is independently associated with lower gestational age at birth, first study period, and PPROM.

Small studies have linked invasive intrauterine procedures, such as chorionic villus sampling, amniocentesis and fetal blood sampling, to the occurrence of EOS (André et al., 2000; Brambati et al., 1990; d'Ercole et al., 2003; Hamoda \& Chamberlain, 2002; Kim et al., 2015; Soman et al., 1985; Workman \& Philpott-Howard, 1997). Reports on the frequency of EOS after laser surgery are, however, lacking. EOS is usually caused by bacterial pathogens transmitted vertically from mother to the fetus perinatally, resulting in intrauterine infection and ensuing EOS (Naeye et al., 1971). Previous studies have suggested a possible association between laser surgery and increased risk of chorioamnionitis (Habli et al., 2009; Meriki et al., 2010; Merz et al., 2010; Rossi et al., 2008; Rustico et al., 2012; Stirnemann et al.,
2012; Yamamoto et al., 2005). In a cohort of 266 TTTS cases treated with laser surgery, Rossi et al. (2008) reported that the risk of iatrogenic PPROM and clinical chorioamnionitis was $38 \%$ and $0 \%$, respectively. However, the diagnosis of chorioamnionitis was not based on histopathological evaluation, and the risk of neonatal EOS was not reported. In another larger cohort of 602 TTTS cases treated with laser surgery, Stirnemann et al. (2012) reported a $4 \%$ incidence of clinical chorioamnionitis, but again, data on neonatal EOS were not described. In a prospective study, Lewi et al. (2008) reported a rate of neonatal sepsis of $4 \%$ in monochorionic twin pregnancies. However, the frequency of neonatal sepsis in the subgroup of TTTS managed with laser surgery was not specified, and the definition of neonatal sepsis was not clearly described. In our study, we found that the rate of proven EOS was $2 \%$ in monochorionic twins managed with laser surgery and $0.4 \%$ in monochorionic twins not managed with laser surgery. Laboratory investigations also showed higher CRP levels and I/T ratio in the TTTS group. Whether these result from bacterial 
infection or post-operative inflammation after laser surgery is not clear.

This study further analyzed the association between several perinatal variables with the occurrence of EOS in the subgroup of TTTS treated with laser surgery. We found that lower gestational age at birth, first study period, and PPROM were independently associated with EOS after laser surgery. Iatrogenic PPROM is a known risk associated with invasive intrauterine procedures. In accordance with previous studies, we also found an increased risk of PPROM (28\%) after laser surgery (Rossi et al., 2008; Yamamoto et al., 2005). PPROM may facilitate the invasion of microorganisms into the amniotic cavity, leading to histopathological and/or clinical chorioamnionitis and resulting in fetuses exposed to high risk of infection (Kim et al., 2015; Wortham et al., 2016). PPROM may also lead to premature delivery, which is a known risk factor for both EOS as well as late onset sepsis (Martius et al., 1999; Schrag et al., 2006; Schuchat et al., 2000). In addition, in neonates with lower gestational age at birth, the innate, and adaptive immunity may be more immature, increasing the risk of infection (Wynn \& Levy, 2010). Lastly, we also found an increased risk of EOS in the first study period. The decrease in risk of infection in the second, most recent study period might be a direct effect of the learning curve related to laser surgery. Increased experience and improved laser technique within recent years may result in a reduction of procedure-related complications (Peeters et al., 2014).

Univariate analysis in this study also showed that a shorter interval between laser surgery and birth and anterior placenta are associated with EOS. However, after correction in multivariate analysis, they were no longer associated with the occurrence of EOS. A shorter interval between laser surgery and birth might be a result of PPROM and chorioamnionitis and result in premature delivery. Anterior placenta increases the complexity of the fetal surgical intervention and may thus increase the risk of perinatal infection due to a longer operation time and a higher risk of complications such as iatrogenic PPROM (Yamamoto et al., 2005). This hypothesis should be further explored in other cohorts.

An important asset of this study is that it is a large prospective cohort study, including monochorionic twins with and without TTTS. Furthermore, it is the first study to investigate the occurrence of EOS after laser surgery for TTTS, an important evaluation of an invasive procedure, which is increasingly being used throughout the world. However, our study has several limitations for which the results should be carefully interpreted. An important limitation is that histopathological evaluation of the placenta was not routinely performed. In addition, by excluding monochorionic twin pregnancies with fetal demise from this study, we may have introduced a selection bias. However, these cases had to be excluded since sepsis workup was not performed in these neonates, preventing diagnosis of EOS. If demise in these cases was due to perinatal infection, the rate of EOS in the TTTS group would have been higher and our data may underestimate the true occurrence of EOS. On the other hand, neonatal infection in some cases in the TTTS group could be the result of prematurity due to immature immune system and not a direct result of the laser surgery. Therefore, our data may also overestimate the true risk of infection after laser. However, studying this aspect is not considered ethical, since the majority of TTTS is currently managed with laser surgery (Roberts et al., 2014; Senat et al., 2004).

\section{Conclusions}

The occurrence of EOS in TTTS managed with laser surgery is low, but increased compared to uncomplicated monochorionic twins. Future studies and developments focusing on improvement of laser technique and instruments may reduce the risk of (iatrogenic) PPROM, chorioamnionitis, and perinatal sepsis. Neonatologists should be aware of the risk of EOS when caring for newborns treated with laser surgery for TTTS during pregnancy.

\section{References}

André, P., Thébaud, B., Guibert, M., Audibert, F., LacazeMasmonteil, T., \& Dehan, M. (2000). Maternal-fetal staphylococcal infections: A series report. American Journal of Perinatology, 17, 423-428.

Brambati, B., Lanzani, A., \& Tului, L. (1990). Transabdominal and transcervical chorionic villus sampling: Efficiency and risk evaluation of 2,411 cases. American Journal of Medical Genetics, 164, 160-164.

Chalouhi, G. E., Essaoui, M., Stirnemann, J., Quibel, T., Deloison, B., Salomon, L., \& Ville, Y. (2011). Laser therapy for twin-to-twin transfusion syndrome (TTTS). Prenatal Diagnosis, 31, 637-646.

d'Ercole, C., Shojai, R., Desbriere, R., Chau, C., Bretelle, F., Piéchon, L., \& Bouli, L. (2003). Prenatal screening: Invasive diagnostic approaches. Child's Nervous System, 19, 444-447.

Dutch Society of Obstetrics and Gynaecology [Nederlandse vereniging voor obstetrie en gynaecologie]. (2012). Prevention of neonatal group-b streptococcal disease in the Netherlands [Preventie van neonatale groep-B streptokokkenziekte] version 2.0. NVOG-richtlijn 2012.

Habli, M., Bombrys, A., Lewis, D., Lim, FY., Polzin, W., Maxwell, R., \& Crombleholme, T. (2009). Incidence of complications in twin-twin transfusion syndrome after selective fetoscopic laser photocoagulation: A single-center experience. American Journal of Obstetrics and Gynecology, 201, 417.e1-7.

Hamoda, H., \& Chamberlain, P. F. (2002). Clostridium welchii infection following amniocentesis: A case report and review of the literature. Prenatal Diagnosis, 22, 783-785. 
Kim, C. J., Romero, R., Chaemsaithong, P., Chaiyasit, N., Yoon, B. H., \& Kim, Y. M. (2015). Acute chorioamnionitis and funisitis: Definition, pathologic features, and clinical significance. American Journal of Obstetrics and Gynecology, 213, S29-S52.

Lewi, L., Jani, J., Blickstein, I., Huber, A., Gucciardo, L., Van Mieghem, T., ... Deprest, J. (2008). The outcome of monochorionic diamniotic twin gestations in the era of invasive fetal therapy: A prospective cohort study. American Journal of Obstetrics and Gynecology, 199, 514.e1-8.

Martius, J. A., Roos, T., Gora, B., Oehler, M. K., Schrod, L., Papadopoulos, T., \& Gross, U. (1999). Risk factors associated with early-onset sepsis in premature infants. European Journal of Obstetrics \& Gynecology and Reproductive Biology, 85, 151-158.

Meriki, N., Smoleniec, J., Challis, D., \& Welsh, A. W. (2010). Immediate outcome of twin-twin transfusion syndrome following selective laser photocoagulation of communicating vessels at the NSW fetal therapy centre. Australian and New Zealand Journal of Obstetrics and Gynaecology, 50, 112119.

Merz, W., Tchatcheva, K., Gembruch, U., \& Kohl, T. (2010). Maternal complications of fetoscopic laser photocoagulation (FLP) for treatment of twin-twin transfusion syndrome (TTTS). Journal of Perinatal Medicine, 38, 439-443.

Naeye, R. L., Dellinger, W. S., \& Blanc, W. A. (1971). Fetal and maternal features of antenatal bacterial infections. Journal of Pediatrics, 79, 733-739.

Peeters, S. H. P., Van Zwet, E. W., Oepkes, D., Lopriore, E., Klumper, F. J., \& Middeldorp, J. M. (2014). Learning curve for fetoscopic laser surgery using cumulative sum analysis. Acta Obstetricia et Gynecologica Scandinavica, 93, 705-711.

Polin, R. A. (2012). Management of neonates with suspected or proven early-onset bacterial sepsis. Pediatrics, 129, 10061015.

Quintero, R. A., Morales, W. J., Allen, M. H., Bornick, P. W., Johnson, P. K., \& Kruger, M. (1999). Staging of twin-twin transfusion syndrome. Journal of Perinatology, 19, 550-555.

Roberts, D., Neilson, J. P., Kilby, M. D., \& Gates, S. (2014). Interventions for the treatment of twin-twin transfusion syndrome. Cochrane Database of Systematic Reviews, Issue 1. Art. No.: CD002073. DOI: 10.1002/14651858.CD002073.pub3.

Rossi, A. C., Kaufman, M. A., Bornick, P. W., \& Quintero, R. A. (2008). General vs local anesthesia for the percutaneous laser treatment of twin-twin transfusion syndrome. American Journal of Obstetrics and Gynecology, 199, 137e1-7.

Rustico, M. A., Lanna, M. M., Faiola, S., Schena, V., Dell'avanzo, M., Mantegazza, V., ... Ferrazzi, E. (2012). Fetal and maternal complications after selective fetoscopic laser surgery for twin-to-twin transfusion syndrome: A single-center experience. Fetal Diagnosis and Therapy, 31, 170-178.

Salomon, L. J., Ortqvist, L., Aegerter, P., Bussieres, L., Staracci, S., Stirnemann, J. J., ... Ville, Y. (2010). Long-term developmental follow-up of infants who participated in a randomized clinical trial of amniocentesis vs laser photocoagulation for the treatment of twin-to-twin trans- fusion syndrome. American Journal of Obstetrics and Gynecology, 203, 444.e1-7.

Schrag, S. J., Hadler, J. L., Arnold, K. E., Martell-Cleary, P., Reingold, A., \& Schuchat, A. (2006). Risk factors for invasive, early-onset Escherichia coli infections in the era of widespread intrapartum antibiotic use. Pediatrics, 118, 570576.

Schuchat, A., Zywicki, S. S., Dinsmoor, M. J., Mercer, B., Romaguera, J., O’Sullivan, M. J., ... Levine, O. S. (2000). Risk factors and opportunities for prevention of early-onset neonatal sepsis: A multi-center case-control study. Pediatrics, 105, 21-26.

Senat, M. V., Deprest, J., Boulvain, M., Paupe, A., Winer, N., \& Ville, Y. (2004). Endoscopic laser surgery versus serial amnioreduction for severe twin-to-twin transfusion syndrome. New England Journal of Medicine, 351, 136-144.

Slaghekke, F., Kist, W. J., Oepkes, D., Pasman, S. A., Middeldorp, J. M., Klumper, F. J., ... Lopriore, E. (2010). Twin anemia-polycythemia sequence: Diagnostic criteria, classification, perinatal management and outcome. Fetal Diagnosis and Therapy, 27, 181-190.

Slaghekke, F., Lewi, L., Middeldorp, J. M., Weingertner, A.-S., Klumper, F. J., Dekonick, P., ... Lopriore, E. (2014). Residual anastomoses in twin-twin transfusion syndrome after laser: The Solomon randomized trial. American Journal of Obstetrics and Gynecology, 211, 285.e1-285.e7.

Slaghekke, F., Lopriore, E., Lewi, L., Middeldorp, J. M., van Zwet, E. W., Weingertner, A. S., ... Oepkes, D. (2014). Fetoscopic laser coagulation of the vascular equator versus selective coagulation for twin-to-twin transfusion syndrome: An open-label randomized controlled trial. Lancet, 383, 2144-2151.

Soman, M., Green, B., \& Daling, J. (1985). Risk factors for early neonatal sepsis. American Journal of Epidemiology, 121, 712719.

Stirnemann, J. J., Quibel, T., Essaoui, M., Salomon, L. J., Bussieres, L., \& Ville, Y. (2012). Timing of delivery following selective laser photocoagulation for twin-to-twin transfusion syndrome. American Journal of Obstetrics and Gynecology, 207, 127.e1-e6.

Stoll, B. J., Hansen, N. I., Sánchez, P. J., Faix, R. G., Poindexter, B. B., Van Meurs, K. P., ... Higgins, R. D., \& Eunice Kennedy Shriver National Institute of Child Health and Human Development Neonatal Research Network. (2011). Early onset neonatal sepsis: The burden of group B streptococcal and E coli disease continues. Pediatrics, 127, 817-826.

Weston, E. J., Pondo, T., Lewis, M. M., Martell-Cleary, P., Morin, C., Jewell, B., ... Schrag, S. J. (2011). The burden of invasive early-onset neonatal sepsis in the United States, 2005-2008. Pediatric Infectious Disease Journal, 30, 937-941.

Workman, M. R., \& Philpott-Howard, J. (1997). Risk of fetal infection from invasive procedures. Journal of Hospital Infection, 35, 169-173.

Wortham, J. M., Hansen, N. I., Schrag, S. J., Hale, E., Van Meurs, K., Sánchez, P. J., ... Stoll, B. J., for the Eunice Kennedy Shriver National Institute of Child Health and Human Development Neonatal 
Research Network. (2016). Chorioamnionitis and cultureconfirmed, early-onset neonatal infections. Pediatrics, 137, $1-11$.

Wynn, J. L., \& Levy, O. (2010). Role of innate host defenses in susceptibility to early-onset neonatal sepsis. Clinics in Perinatology, 37, 307-337.
Yamamoto, M., El Murr, L., Robyr, R., Leleu, F., Takahashi, Y., \& Ville, Y. (2005). Incidence and impact of perioperative complications in 175 fetoscopy-guided laser coagulations of chorionicplate anastomoses in fetofetal transfusion syndrome before 26 weeks of gestation. American Journal of Obstetrics and Gynecology, 193, 1110-1116. 